\title{
Do Mutual Fund Managers Time Market Sentiment?
}

\author{
Jun-Hao Li ${ }^{1}$, Chun-Fan You ${ }^{2} \&$ Chin-Sheng Huang ${ }^{1}$ \\ ${ }^{1}$ Department of Finance, National Yunlin University of Science \& Technology, Yunlin, Taiwan, R.O.C. \\ ${ }^{2}$ Department of Finance, Chihlee University of Technology, New Taipei City, Taiwan, R.O.C. \\ Correspondence: Chun-Fan You, Department of Finance, Chihlee University of Technology, New Taipei City, \\ Taiwan, R.O.C. Tel: 886-2-2257-6167. E-mail: steveyou@ mail.chihlee.edu.tw
}

Received: May 28, 2020

Accepted: June 28, 2020

Online Published: October 5, 2020

doi:10.5430/ijfr.v11n5p527

URL: https://doi.org/10.5430/ijfr.v11n5p527

\begin{abstract}
This paper examines whether fund managers can adjust the exposure of portfolio to time market sentiment, thus expanding the new dimension of the study of mutual fund managers' timing ability. Using the data of Chinese open-end equity funds from January 2010 to December 2019, based on the CICSI sentiment index developed by Yi and Mao (2009), we find strong evidence that Chinese mutual fund managers have sentiment ability during the sample period. In addition, the funds with positive sentiment timing ability outperforms those without such by $2.20 \%$ per year, and the longer the fund survives, the more likely for it to have sentiment timing ability. Our findings remain robust even after controlling the impact of bull and bear market on China's A-share market in 2015, market timing, volatility timing and liquidity timing, and after using three new sentiment indicators to verify the finding, three indicators being the net buying amount of northward capital, the net buying amount of financing, and the net ratio of limit up.
\end{abstract}

Keywords: sentiment timing, mutual fund, China's A-share

\section{Introduction}

Whether mutual fund managers have the timing ability is an old and unresolved issue. By checking whether fund managers can adjust their portfolio exposure based on their predictions of market returns, Treynor and Mazuy (1966) creatively developed a model to measure the market timing ability. Later, Busse (1999) and Cao, Chen, Liang and Lo (2013) respectively proposed other measures to identify the volatility timing and liquidity timing ability of fund managers. In this paper, the timing ability of mutual fund managers for market sentiment is examined in order to explore this classic issue from a novel behavioral economics perspective. Specifically, there is an examination of whether fund managers adjust their portfolio exposure when market sentiment changes.

Market sentiment refers to the overall attitude adopted by investors toward the financial market. The optimistic or pessimistic expectation on the market environment by investors determines the bias of market sentiment. In recent years, market sentiment has become one of the most closely watched indicators. Therefore, it has also attracted the attention of a lot of researchers. Brown and Cliff (2005) believed that when the optimistic sentiment drives the asset price above its fundamental value, the subsequent fall of market sentiment will lead to the drop in market prices, thus leading to temporary low asset benefits at the end of the period of optimistic sentiment. Such scholars as Hirshleifer (2001), Baker and Wurgler (2006), Kumar and Lee (2006), and Lepori (2016) also proved the impact of investor sentiment on the benefits of securities. Thus, it seems particularly vital to add the sentiment factor in a timing study.

The discussion is about whether mutual fund managers have sentiment timing ability according to the following reasons. As the decision maker of the large investment institution, the fund manager relatively has perfect financial knowledge, research teams and investment vehicles. Fund managers get the funds and trust from many investors, meanwhile, managers charge high management fees from them, so there is always an interesting question about whether fund managers can bring excess returns to investors. Previous research on market sentiment has mainly focused on futures, hedge funds, and corporate investment. For example, the research, based on the sentiment timing ability of hedge fund managers, has found that hedge funds with negative sentiment exposure performed better than hedge funds with positive sentiment exposure (Zheng, Osmer and Zhang, 2018). However, the research on mutual fund managers' sentiment timing ability is a new topic.

Research on timing ability or market sentiment of fund managers is mainly aimed at developed economies, such as 
Andreu, Matallín-Sáez and Sarto (2018), Oliveira, Salen, Curto and Ferreira (2018), and Clare, O'Sullivan, Sherman and Zhu (2019). Only few literatures have some researches for emerging economies, for example, Wattanatorn and Tansupswatdikul (2018). With the liberalization and integration of emerging economies, there has been a wider road to the market-open to some extent and a very substantial increase in the amount of investment for emerging economies (Ghosh, Qureshi, Kim and Zalduendo, 2014). It should be noted that foreign investment accounts for the proportion of GDP in emerging markets (Ahmed and Zlate, 2014). China, as the second largest economy in the world, is also the largest emerging economy in the world. In 2018, FTSE Russell CEO (Mark Makepeace) estimated that 2.5 trillion US dollars (about 17.7 trillion yuan) would flow into the Chinese securities market within the next five to ten years. Under this background, it seems more meaningful to analyze the Chinese market. The Chinese market with its particularity in some aspects creates an ideal environment to observe whether Chinese fund managers have timing ability or not.

First of all, the Chinese securities market consists of relatively immature retail investors (Lee, Li and Wang, 2010). Liao, Zhang and Zhang (2017) reported that by the end of 2012, institutional investors had accounted for only less than $15 \%$ of the securities market share in China while this figure was over $60 \%$ in the United States. The China Household Finance Survey in 2014 shows that around one third of Chinese investors have not received basic higher education. However, the level of financial knowledge is strongly correlated with investment performance (Muñoz and Vicente, 2018), and investors without receiving higher education will bring about more frequent trading (Jiang, Liao, Wang and Xiang, 2020). The irrational preference and investment characteristics of individual investors have led to predictability in China's stock market (Yi and He, 2016). Such a special investment structure and investment sentiment may enable fund managers in China to commit arbitrage more easily.

Secondly, mutual fund has enjoyed rapid development in China in a short period. The limitation from market system and the absence of short-mechanism have led to dramatic fluctuation in China's securities market, particularly when economic shocks crop up (Tang, Wang and Xu, 2012; Jun, Li and Shi, 2014). Specifically, China did not roll out its index options until the end of 2019 and before that it was impossible to use options for hedging. Under the negative impact of the sharp drop of the stock market in 2015, the government substantially increased the proportion of futures margin and limit open position, leading to the sharp shrinking in the volume and open Interest of stock index futures and inability for investors to conduct normal hedging. Owing to the scarcity of shortable stocks, the Chinese government increased the number of subject shares of short selling and margin trading from 950 to 1,600 in 2019. Even so, they still simply account for only $40 \%$ in A share, which cannot meet the hedging demand. These several major hedging means impose a high requirement on investor's capital and it's impossible for ordinary individual investors to adopt these means for hedging. In the Chinese market dominated by retail investors, the phenomenon of chasing the winner and cutting the loser has been intensified.

Finally, China's stock market is highly susceptible to the influence of policy changes. For example, the government has issued policies to limit dividend or release supportive policies in a certain industry. These policy incidents will substantially influence the trend of China's stock market (Wang, Tsai and $\mathrm{Li}, 2017$ ). Compared with developed economies, China suffers from serious information asymmetry (Morck, Yeung and Yu, 2000). Compared with individual investors, institutional investors, especially funds, are stronger in information mining (Liao, Liu and Wang, 2011). Institutional investors may prejudge the release of policies and regulations through professional analysis. Additionally, under short-sales constraints in China, individual investors can hardly commit arbitrage on mispriced stocks quickly (Chen, Kim, Yao and Yu, 2010). All these have provided funds with the information advantages for timing arbitrage and similar incidents have sparked more intensive timing behaviors.

On the basis of the Cao, Simin and Wang (2013) research on fund liquidity timing ability, we extended some literatures about mutual fund managers' sentiment timing ability. Unlike the research which focuses on sentiment coefficients to analyze how hedge fund adjustment exposure is (Zheng, Osmer and Zhang, 2018), we mainly research the impact of sentiment coefficients in different directions on fund performance. In addition, we have developed three new sentiment indicators, such as net buying amount of northward capital, net buying amount of financing, and net ratio of limit up.

Past literatures usually use the Baker-Wurgler Index (Baker and Wurgler, 2006) to measure the market sentiment level. Yi and Mao (2009) think there is some problem because of the single measurement indicator and the impure measurement results by using this method. According to this idea, they built a CICSI index (Chinese stock market investor sentiment composite index), which includes six indicators, such as fund discount rate, turnover rate, IPO quantity, IPO first-day return, consumer confidence index and the number of accounts opened by new investors. Based on the CICSI index, we conduct the research on fund sentiment timing ability. 
We carried out a variety of sentiment timing tests by using monthly data of 183 funds from January 2010 to December 2019. We construct a regression model to test how the coefficient of the fund changes with the market sentiment. Our results show that fund managers can adjust their exposure according to the sentiment. Funds with positive sentiment timing outperform other funds, and the longer the fund survives, the more likely for it to have sentiment timing ability. Our findings remain robust even after controlling the impact of bull and bear market on China's A-share market in 2015, market timing, volatility timing and liquidity timing, and after using three new sentiment indicators to verify the finding.

The remainder of the paper proceeds as follows, section 2 introduces the data and research methods, section 3 is the results of empirical analysis, section 4 is the further test, and section 5 is the conclusion.

\section{Data and Methodology}

\subsection{Chinese Mutual Funds}

Our mutual fund data comes from RESSET financial research dataset (RESSET), and the rest comes from the China Stock Market \& Accounting Research (CSMAR). We used the monthly data of Chinese open-end equity funds from January 2010 to December 2019, and obtained 966 funds data from the database. We excluded 580 index funds or funds invested in the non- mainland China market. To ensure the stability of fund operation, we used the funds with the least number of 36 months trading data, and finally, we had 183 sample funds.

Table 1. Summary statistics

\begin{tabular}{clllll}
\hline & Mean & STD & $25 \%$ & Median & $75 \%$ \\
\hline$r_{p}$ & 0.66 & 6.76 & -2.58 & 0.76 & 3.88 \\
$R_{m}$ & 0.16 & 6.84 & -4.56 & 0.14 & 3.82 \\
$S M B$ & 0.63 & 5.13 & -2.38 & 0.39 & 3.67 \\
$H M L$ & -0.05 & 3.74 & -1.62 & 0.14 & 1.40 \\
$S$ & 0.00 & 5.07 & -3.46 & 0.25 & 3.32 \\
\hline
\end{tabular}

This table reports data summary statistics. Returns of mutual funds $\left(r_{p}\right)$ summarize the excess return of open-end equity funds. The other variables summarized in the table include market excess returns ( $R_{m}$, CSI 300 index), size factor $(S M B)$, book-to-market ratio factor $(H M L)$, and market sentiment measure (S, CICSI index). All data are reported as percent per month. The sample period is from January 2010 to December 2019.

Table 1 reports the summary statistics of Chinese mutual funds. During the sample period, the average monthly return of all funds was $0.66 \%$ (about $8.21 \%$ per year), and the standard deviation was $6.76 \%$. During the same period, the market return was $0.16 \%$ and the standard deviation was $6.84 \%$. It can be seen that during the sample period, the sample funds generally show better performance and lower volatility than the market.

\subsection{Methodology}

Based on the three-factor model proposed by Fama and French (1992), we study the timing ability of Chinese fund managers:

$$
r_{p t}=\alpha_{p}+\beta_{m p} R_{m t}+\beta_{S M B, p} S M B_{t}+\beta_{H M L, p} H M L_{t}+\varepsilon_{p t}
$$

Where $r_{p t}$ is the monthly return of fund $p$ minus the risk-free interest rate in period $t$, this paper defines the monthly one-year deposit rate as the risk-free interest rate. Because most of the performance reference standards of Chinese mutual funds are based on the CSI 300 index, this paper defines the CSI 300 index as the market index, and $R_{m t}$ is the monthly return of the market index minus the risk-free interest rate in period $t . S M B_{t}$ and $H M L_{t}$ are the returns of the simulated portfolio in period $t$ based on scale and book to market ratio, respectively.

In order to test the ability of sentiment timing ability, we follow the traditional literature on timing, using a first-order Taylor series expansion to express the market Beta as a linear function of market sentiment that exceeds the average of its time series:

$$
\beta_{m p}=\beta_{0 m p}+\gamma_{m p}\left(S_{m t}-\bar{S}_{m}\right)
$$

Where $S_{m t}$ is the market sentiment measure in period $t, \bar{S}_{m}$ is the average of market sentiment measures for all 
months in the sample. By inserting Eq. (2) into Eq. (1), we can get our three-factor sentiment timing model:

$$
r_{p t}=\alpha_{p}+\beta_{0 m p} R_{m t}+\gamma_{m p}\left(S_{m t}-\bar{S}_{m}\right) R_{m t}+\beta_{S M B, p} S M B_{t}+\beta_{H M L, p} H M L_{t}+\varepsilon_{p t}
$$

As the introduction says, we use the CICSI index to construct our measure of market sentiment:

$$
C I C S I=0.231 D C E F+0.224 T U R N+0.257 I P O N+0.322 I P O R+0.268 C C I+0.405 N I A
$$

Where $D C E F$ is the closed-end fund discount rate, which is weighted average monthly value. TURN is the market turnover rate, which is calculated by the average ratio of monthly trading volume to monthly market value. IPON is the number of IPOs in the current month. IPOR is the average return weighted by the number of IPO shares, CCI is the consumer confidence index, and NIA is the logarithm of the number of new investors' accounts opened last month.

\section{Empirical Analysis}

In this section, we examine the sentiment timing ability of mutual fund managers, and compare the differences of returns and volatility between positive timing, negative timing, and control groups. We tested whether the results excluding 2015 were robust (China's A-share market experienced a complete bull and bear market in 2015), We also tested the sentiment timing ability of mutual fund managers by adding market, volatility and liquidity impact, and grouping the funds according to their survival duration.

\subsection{Sentiment Timing Test}

First, we use the sentiment timing measure constructed by the CICSI index to test the timing ability of mutual fund managers. We reported the results in Table 2.

\begin{tabular}{|c|c|c|c|c|c|}
\hline \multicolumn{6}{|c|}{ Panel A Percentage of funds } \\
\hline $\mathrm{t} \leq-2.326$ & $\mathrm{t} \leq-1.960$ & $\mathrm{t} \leq-1.645$ & $\mathrm{t} \geq 1.645$ & $t \geq 1.960$ & $\mathrm{t} \geq 2.326$ \\
\hline 0.00 & 0.55 & 0.55 & 32.79 & 22.95 & 15.85 \\
\hline \multicolumn{6}{|c|}{ Panel B Returns comparison } \\
\hline & & \multicolumn{2}{|l|}{ Mean } & \multicolumn{2}{|r|}{ STD } \\
\hline \multicolumn{2}{|c|}{ Positive timing } & \multicolumn{2}{|l|}{0.78} & \multicolumn{2}{|r|}{7.23} \\
\hline \multicolumn{2}{|c|}{ Negative timing } & \multicolumn{2}{|l|}{-0.14} & \multicolumn{2}{|r|}{6.02} \\
\hline \multicolumn{2}{|c|}{ Control group } & \multicolumn{2}{|l|}{0.61} & \multicolumn{2}{|r|}{6.54} \\
\hline
\end{tabular}

Table 2. Test of sentiment timing

Regression with Eq. (3):

$$
r_{p t}=\alpha_{p}+\beta_{0 m p} R_{m t}+\gamma_{m p}\left(S_{m t}-\bar{S}_{m}\right) R_{m t}+\beta_{S M B, p} S M B_{t}+\beta_{H M L, p} H M L_{t}+\varepsilon_{p t}
$$

Panel A summarizes the distribution of t-statistics for the timing coefficients. We use the CICSI sentiment measure to estimate the sentiment timing ability. Columns 2 to 7 list the percentage of funds which t-statistics of sentiment timing coefficient exceed the indicated values. Panel B reports the Mean and standard deviation of returns for positive timing ( $\mathrm{t} \geq 1.645)$, negative timing $(\mathrm{t} \leq 1.645)$, and control group $(-1.645<\mathrm{t}<1.645)$.

In Panel A, 32.79\% of the fund managers' sentiment timing coefficient's t-statistics greater than or equal to 1.645 (Later in this paper, the fund managers' sentiment timing coefficient's t-statistics greater than or equal to 1.645 are defined as positive timing, t-statistics less than or equal to -1.645 are defined as negative timing, and the rest are defined as control group), in contrast, only $0.55 \%$ of the funds are negative timing. The results show that most of the funds with sentiment timing ability are sentiment liker during the sample period. They judge that when market sentiment rises (falls), returns will also increase (decrease), so increase (decrease) portfolio exposure to achieve better performance.

In Panel $\mathrm{B}$, because the percentage of negative timing is too small to achieve stable results, we only compared the positive timing and control group. Their average monthly returns are $0.78 \%$ and $0.61 \%$, respectively, with a difference of $0.17 \%$ (annualized difference about $2.20 \%$ ), and their standard deviations are $7.23 \%$ and $6.54 \%$, respectively. It can be seen that the return and standard deviation of positive timing are the highest, indicating that in the sample period, positive timing funds can provide better performance by adjusting portfolio exposure. The 
standard deviation also confirms the theme of positive timing. When market sentiment rise (fall), increasing (reducing) exposure will easily lead to the phenomenon of chasing up and killing down, making the standard deviation of positive timing the highest among the three groups.

\subsection{China's A-share Bull and Bear Market Shocks in 2015}

In order to ensure that our results are not affected by the bull and bear market of China's A-share in 2015, we excluded the data from January 2015 to December 2015, and we repeatedly tested Eq. (3) and reported the results in Table 3.

Table 3. Tests of sentiment timing: excluding the bull and bear market shocks in 2015

\begin{tabular}{lllllll}
\hline \multicolumn{1}{l}{ Percentage of funds } & & & & \\
\hline & $\mathrm{t} \leq-2.326$ & $\mathrm{t} \leq-1.960$ & $\mathrm{t} \leq-1.645$ & $\mathrm{t} \geq 1.645$ & $\mathrm{t} \geq 1.960$ & $\mathrm{t} \geq 2.326$ \\
\hline CICSI & 0.00 & 0.00 & 0.00 & 31.69 & 22.40 & 15.30 \\
\hline
\end{tabular}

Regression with Eq. (3):

$$
r_{p t}=\alpha_{p}+\beta_{0 m p} R_{m t}+\gamma_{m p}\left(S_{m t}-\bar{S}_{m}\right) R_{m t}+\beta_{S M B, p} S M B_{t}+\beta_{H M L, p} H M L_{t}+\varepsilon_{p t}
$$

This table summarizes the distribution of t-statistics for the timing coefficients. We use the CICSI sentiment measure to estimate the sentiment timing ability of sample after excluding the data from January 2015 to December 2015. Columns 2 to 7 list the percentage of funds which t-statistics of sentiment timing coefficient exceed the indicated values.

Compared with the results of Table 2, it can be seen that the negative timing has been lost, while the percentage of positive timing has only slightly decreased by $1.1 \%$. It shows that the sentiment timing ability of fund managers is hardly affected by the bull and bear markets in 2015 , and even after excluding the data in 2015 , our results are still robust.

\subsection{Market Timing, Volatility Timing, and Liquidity Timing}

Traditional fund timing literature usually discusses market, volatility and liquidity, such as Treynor and Mazuy (1966), Busse (1999), Cao, Simin and Wang (2013). Many literatures have verified the correlation between these factors and market returns, which may affect the robustness of sentiment timing factors. Therefore, we add these three factors into regression to control:

$$
\begin{gathered}
r_{p t}=\alpha_{p}+\beta_{0 m p} R_{m t}+\gamma_{m p}\left(S_{m t}-\bar{S}_{m}\right) R_{m t}+\delta_{m p} R_{m t}^{2}+\theta_{m p}\left(V_{m t}-\bar{V}_{m}\right) R_{m t}+\varphi_{m p}\left(L_{m t}-\bar{L}_{m}\right) R_{m t}+ \\
\beta_{S M B, p} S M B_{t}+\beta_{H M L, p} H M L_{t}+\varepsilon_{p t}
\end{gathered}
$$

Where $R_{m t}^{2}$ is the market timing factor of T-M model proposed by Treynor and Mazuy (1966). $V_{m t}$ is the market volatility measure in period $t$, we use the standard deviation of market returns of 12 months before period $t$ to calculate market volatility measure, and $\bar{V}_{m}$ is the average value of the market volatility measure of all months. $L_{m t}$ is the market liquidity measure in period $t$, we use the illiquidity index proposed by Amihud (2002) to calculate, and $\bar{L}_{m}$ is the average value of market liquidity measure of all months. We reported the results in Table 4.

Table 4. Tests of sentiment timing: control market, volatility, and liquidity timing

\begin{tabular}{lllllll}
\hline \multicolumn{1}{l}{ Percentage of funds } \\
\hline & $\mathrm{t} \leq-2.326$ & $\mathrm{t} \leq-1.960$ & $\mathrm{t} \leq-1.645$ & $\mathrm{t} \geq 1.645$ & $\mathrm{t} \geq 1.960$ & $\mathrm{t} \geq 2.326$ \\
\hline CICSI & 0.00 & 1.09 & 1.64 & 18.58 & 13.66 & 7.65 \\
\hline
\end{tabular}

Regression with Eq. (5):

$$
\begin{gathered}
r_{p t}=\alpha_{p}+\beta_{0 m p} R_{m t}+\gamma_{m p}\left(S_{m t}-\bar{S}_{m}\right) R_{m t}+\delta_{m p} R_{m t}^{2}+\theta_{m p}\left(V_{m t}-\bar{V}_{m}\right) R_{m t}+\varphi_{m p}\left(L_{m t}-\bar{L}_{m}\right) R_{m t}+\beta_{S M B, p} S M B_{t} \\
+\beta_{H M L, p} H M L_{t}+\varepsilon_{p t}
\end{gathered}
$$

This table summarizes the distribution of t-statistics for the timing coefficients. We control the affect of market, volatility and liquidity timing factors. We use the CICSI sentiment measure to estimate the sentiment timing ability. 
Columns 2 to 7 list the percentage of funds which t-statistics of sentiment timing coefficient exceed the indicated values.

After controlling the three factors of market, volatility and liquidity, it can be seen that the percentage of negative timing slightly increased to $1.64 \%$. While the percentage of positive timing decreased to $18.58 \%$, but its percentage in funds with sentiment timing ability is still higher than $90 \%$. It shows that even after controlling the effect of many different timing factors, most of the funds with sentiment timing ability are still sentiment liker, and our results are still robust.

\subsection{Survival Duration Comparison}

In order to compare the effect of different survival durations on the sentiment timing ability of funds, we divided the sample funds into two groups according to their survival durations: group 1 (less than 60 months, 138 funds) and group 2 (more than or equal to 60 months, 45 funds). We repeatedly tested Eq. (3) and reported the results in Table 5.

Table 5. Tests of sentiment timing: survival duration comparison

\begin{tabular}{lllllll}
\hline \multicolumn{1}{l}{ Percentage of funds } & \multicolumn{5}{l}{} \\
\hline & $\mathrm{t} \leq-2.326$ & $\mathrm{t} \leq-1.960$ & $\mathrm{t} \leq-1.645$ & $\mathrm{t} \geq 1.645$ & $\mathrm{t} \geq 1.960$ & $\mathrm{t} \geq 2.326$ \\
\hline Group 1 & 0.00 & 0.72 & 0.72 & 27.54 & 18.84 & 11.59 \\
Group 2 & 0.00 & 0.00 & 0.00 & 48.89 & 35.56 & 28.89 \\
\hline
\end{tabular}

Regression with Eq. (3):

$$
r_{p t}=\alpha_{p}+\beta_{0 m p} R_{m t}+\gamma_{m p}\left(S_{m t}-\bar{S}_{m}\right) R_{m t}+\beta_{S M B, p} S M B_{t}+\beta_{H M L, p} H M L_{t}+\varepsilon_{p t}
$$

This table summarizes the distribution of t-statistics for the timing coefficients. We use the CICSI sentiment measure to estimate the sentiment timing ability of two survival duration groups. Columns 2 to 7 list the percentage of funds which t-statistics of sentiment timing coefficient exceed the indicated values.

In this table, we compare group 1 and group 2 and find that the percentage of positive timing is as high as $48.89 \%$ in group 2 and only $27.54 \%$ in group 1 . Through this grouping test, we believe that the longer the fund lasts in the sample period, the more likely it is to have positive sentiment timing ability.

\section{Further Analysis}

In this section, in order to verify the robustness of the results under different sentiment indicators, we constructed three new sentiment indicators to test the sentiment timing ability of mutual fund managers, and compare the differences of returns and volatility between positive timing, negative timing, and control groups.

The first is northward capital. China's A-share market does not allow international capitals to directly participate in transactions for the time being, but Hong Kong, as an international financial center, is also a special administrative region of China. Therefore, after 2014, China has successively opened the mutual flow channels between the mainland and Hong Kong (Shang Hai-Hong Kong stock connect and Shen Zhen-Hong Kong stock connect), which can be used by international capitals to enter China. Because the mainland is located in the north of Hong Kong, the capitals that enter the mainland through Hong Kong are collectively referred to as northward capital. As many international institutions and investors with high investment levels use this channel to enter China, it can be seen through observation that they have a clear leading position in the trend of A-share, and multiple accurate bottom reading has earned them the title of "Smart Money". When the net buying amount of northward capital (buying amount minus selling amount) increases, it means that "Smart Money" is buying and market sentiment is rising, and vice versa. Up to now, the trend of northward capital has become one of the important reference indicators of market sentiment.

The second is buying amount of financing. China's A-share opened financing trading in 2010, further improving financial market instruments. The difference from northward capital, which represents international capital, is that financing trading represents the sentiment of high-risk investors. We use the difference between the buying amount of financing and the repayment amount of financing. When the net buying amount of financing increases (decreases), investors tend to buy (sell), and market sentiment rises (falls).

The third is ratio of limit up. As the introduction said, China's A-share market is still in an environment dominated by 
retail investors, and there are many irrational behaviors. In order to curb over investment, the government sets a limit on the daily price fluctuation, which is called the limit up (limit down) when it reaches the upper limit (lower limit). We calculate the net ratio of limit up per month by using the limit up minus the limit down divided by the total number of stocks. Compared with the first two indicators, the net ratio of limit up is more intuitive, which can be observed or traded at any time in the session, so it represents the overall investor's sentiment preference.

We use the above three indicators: net buying amount of northward capital, net buying amount of financing and net ratio of limit up as new sentiment factors to verify. Because among these three factors, the northward capital data started to be used from November 2014, and our sample period was changed to November 2014 to December 2019. As we were unable to meet the requirement of having at least 36 months' trading data, we removed 1 fund data and changed our sample to 182. We used Eq. (3) for regression, reexamined CICSI and three new sentiment factors, and reported the results in Table 6.

Table 6. Tests of sentiment timing: new sentiment indicators

\begin{tabular}{lllllll}
\hline \multicolumn{7}{l}{ Panel A Percentage of funds } \\
\hline CICSI & $\mathrm{t} \leq-2.326$ & $\mathrm{t} \leq-1.960$ & $\mathrm{t} \leq-1.645$ & $\mathrm{t} \geq 1.645$ & $\mathrm{t} \geq 1.960$ & $\mathrm{t} \geq 2.326$ \\
Northward & 0.55 & 0.55 & 0.55 & 33.52 & 22.53 & 12.64 \\
Financing & 3.85 & 5.49 & 6.59 & 22.53 & 17.03 & 10.99 \\
Limit up & 1.65 & 4.95 & 7.14 & 42.31 & 34.62 & 29.67 \\
\hline Panel B Returns comparison & groups & Mean & & \\
\hline Sentiment factors & Positive timing & 0.78 & STD & \\
\hline CICSI & Negative timing & -0.14 & 7.27 & \\
& & Control group & 0.61 & 6.02 & \\
& Positive timing & 0.73 & 6.63 & \\
\hline Northward & Negative timing & 0.35 & 6.39 & \\
& Control group & 0.66 & 6.51 & \\
\hline Financing & Positive timing & 0.71 & 6.90 & \\
& Negative timing & 0.38 & 7.87 & \\
& Control group & 0.67 & 6.20 & \\
\hline Limit up & Positive timing & 0.68 & 6.58 & \\
& Negative timing & 0.68 & 7.95 & \\
& Control group & 0.64 & 5.51 & \\
\hline
\end{tabular}

Regression with Eq. (3):

$$
r_{p t}=\alpha_{p}+\beta_{0 m p} R_{m t}+\gamma_{m p}\left(S_{m t}-\bar{S}_{m}\right) R_{m t}+\beta_{S M B, p} S M B_{t}+\beta_{H M L, p} H M L_{t}+\varepsilon_{p t}
$$

Panel A summarizes the distribution of t-statistics for the timing coefficients. We use four sentiment factors, CICSI, northward (net buying amount of northward capital), financing (financing), and limit up (net ratio of limit up), to estimate the sentiment timing ability. Columns 2 to 7 list the percentage of funds which t-statistics of sentiment timing coefficient exceed the indicated values. Panel B reports the Mean and standard deviation of returns for positive timing $(\mathrm{t} \geq 1.645)$, negative timing $(\mathrm{t} \leq 1.645)$, and control group $(-1.645<\mathrm{t}<1.645)$.

In Panel A, we see that the CICSI results during the new sample period are basically the same as those in table 2, which further verifies that the CICSI results are still robust in different periods. However, in the northward, the percentage of positive timing decreased significantly, only $8.24 \%$ (25.28\% lower than CICSI), while the percentage of negative timing increased to $2.75 \%$. We speculate that this may be attributed to the fact that the international 
capitals represented by northward capital are mainly value investors, who prefer to adopt the buy and hold strategy, which is relatively less affected by market sentiment, resulting in a sharp drop in the number of funds making sentiment timing based on this indicator. The results of financing and limit up are very good. The positive timing ratio is $22.53 \%$ and $42.31 \%$ respectively, both at a high level. Moreover, the percentage of negative timing in these two factors increased to $6.59 \%$ and $7.14 \%$, respectively. We can use this data to analyze the returns of the three groups.

In Panel B, we see that the results of four factors show that the average return of positive timing is higher than that of negative timing and control group, which further verifies that the positive adjustment of portfolio exposure to sentiment during the sample period can bring better performance to the fund. We are contrary to the research results of Zheng, Osmer, and Zhang (2018) on American hedge funds. It is worth noting that the positive timing in the northward factor has a higher return than the negative timing and control group, while the standard deviation is also lower than the negative timing and control group, indicating that the fund that can timing the market sentiment through the northward factor has the lowest hidden risk while providing a high return. Among the results of CICSI, financing, and limit up factors, the standard deviation of positive timing was similar to that of Table 2, which was higher than that of negative timing and control group. It is also worth noting that in the limit up factor, the negative timing can achieve the same average return $(0.68 \%)$ as the positive timing. In contrast, in CICSI, northward, and financing factors, the average return of the negative timing is lower than the positive timing and the control group.

\section{Conclusion}

This paper conducts sentiment timing ability test on Chinese open-end equity funds. The sample encompasses a 10-year period, 120 months long, from January 2010 to December 2019, covering the volatile downward market of A shares since the financial crisis in 2008, the bull-bear markets in 2015 and the slow repair market thereafter, which is enough to effectively observe fund managers' timing ability in different periods.

Through empirical analysis, it is found that about one-third of the funds have the timing ability for sentiment, which is verified by CICSI index during the sample period, among these funds, the percentage of positive timing funds is as high as $98 \%$. The average monthly returns of positive timing fund, control group and market are $0.78 \%, 0.61 \%$ and $0.16 \%$ respectively, and their annualized returns are about $9.77 \%, 7.57 \%$ and $1.94 \%$ respectively. Besides, the standard deviation of their positive timing fund is $7.27 \%$, which is also higher than $6.54 \%$ of the control group. Thus, it is indicated that the fund returns of the positive timing during the sampling period can not only beat the market, but also reaches an increase of $0.17 \%$ (annualized 2.20\%) compared with the control group's returns. However, the phenomenon of chasing the winner and cutting the market is easy to be caused since the positive timing fund's exposure increases (decreases) when sentiment rises (falls), which has an impact on the stability of performance. After eliminating the impact of bull and bear markets in 2015 and controlling the impact of traditional market, volatility and liquidity timing, the test results are still found to be robust. When dividing the sample funds into two groups according to the survival duration, it is shown that the fund with longer survival duration is more likely to have the sentiment timing ability.

In the further test, three new sentiment indicators are used to compare with CICSI in order to further verify the sentiment timing ability of the fund managers. Similar results are found in CICSI, financing and limit up. The percentage of funds with the sentiment timing ability remains between $30 \%$ and $50 \%$, and the percentage of funds with negative timing in financing and limit up is slightly higher than that of CICSI, reaching about 7\%. Compared with CICSI, there is a significant decrease of the percentage of funds with timing ability of northward factor, which is only about $11 \%$. However, the positive timing fund selected by the northward factor brings about high returns $(0.73 \%)$ with the lowest standard deviation (6.39\%), thus taking into account return and stability. Analyzing other factors, it is found that the fund with positive timing has the highest return and standard deviation compared with the fund with negative timing and control group. Thus, there is a verification of the robustness of our test on the sentiment timing ability of Chinese open-end equity fund managers during the sample period.

\section{References}

Ahmed, S., \& Zlate, A. (2014). Capital flows to emerging market economies: A brave new world?. Journal of International Money and Finance, 48, 221-248. https://doi.org/10.2139/ssrn.2412153

Amihud, Y. (2002). Illiquidity and stock returns: cross-section and time-series effects. Journal of Financial Markets, 5(1), 31-56. https://doi.org/10.1016/S1386-4181(01)00024-6

Andreu, L., Matallín-Sáez, J. C., \& Sarto, J. L. (2018). Mutual fund performance attribution and market timing using portfolio holdings. International Review of Economics \& Finance, 57, 353-370. 
https://doi.org/10.1016/j.iref.2018.02.003

Baker, M. P., \& Wurgler, J. (2006). Investor Sentiment and the Cross-Section of Stock Returns. Journal of Finance, 61(4), 1645-1680. https://doi.org/10.1111/j.1540-6261.2006.00885.x

Brown, G. W., \& Cliff, M. T. (2005). Investor Sentiment and Asset Valuation. The Journal of Business, 78(2), 405-440. https://doi.org/10.2139/ssrn.292139

Busse, J. A. (1999). Volatility timing in mutual funds: Evidence from daily returns. The Review of Financial Studies, 12(5), 1009-1041. https://doi.org/10.1093/rfs/12.5.1009

Cao, C., Chen, Y., Liang, B., \& Lo, A. W. (2013). Can Hedge Funds Time Market Liquidity. Journal of Financial Economics, 109(2), 493-516. https://doi.org/10.2139/ssrn.1537925

Cao, C., Simin, T. T., \& Wang, Y. (2013). Do Mutual Fund Managers Time Market Liquidity. Journal of Financial Markets, 16(2), 279-307. https://doi.org/10.2139/ssrn.1427382

Chen, X., Kim, K. A., Yao, T., \& Yu, T. (2010). On the predictability of Chinese stock returns. Pacific-Basin Finance Journal, 18(4), 403-425. https://doi.org/10.1016/j.pacfin.2010.04.003

Clare, A., O'Sullivan, N., Sherman, M., \& Zhu, S. (2019). The performance of US bond mutual funds. International Review of Financial Analysis, 61, 1-8. https://doi.org/10.1016/j.irfa.2018.12.001

Fama, E. F., \& French, K. R. (1992). The cross-section of expected stock returns. The Journal of Finance, 47(2), 427-465. https://doi.org/10.1111/j.1540-6261.1992.tb04398.x

Ghosh, A. R., Qureshi, M. S., Kim, J. I., \& Zalduendo, J. (2014). Surges. Journal of International Economics, 92(2), 266-285. https://doi.org/10.1016/j.jinteco.2013.12.007

Hirshleifer, D. (2001). Investor psychology and asset pricing. The Journal of Finance, 56(4), 1533-1597. https://doi.org/10.2139/ssrn.265132

Jiang, J., Liao, L., Wang, Z., \& Xiang, H. (2020). Financial literacy and retail investors' financial welfare: Evidence from mutual fund investment outcomes in China. Pacific-basin Finance Journal, https://doi.org/10.1016/j.pacfin.2019.101242

Jun, X., Li, M., \& Shi, J. (2014). Volatile market condition and investor clientele effects on mutual fund flow performance relationship. Pacific-basin Finance Journal, 310-334. https://doi.org/10.1016/j.pacfin.2014.05.002

Kumar, A., \& Lee, C. M. (2006). Retail investor sentiment and return comovements. The Journal of Finance, 61(5), 2451-2486. https://doi.org/10.1111/j.1540-6261.2006.01063.x

Lee, B. S., Li, W., \& Wang, S. S. (2010). The dynamics of individual and institutional trading on the Shanghai Stock Exchange. Pacific-Basin Finance Journal, 18(1), 116-137. https://doi.org/10.2139/ssrn.971419

Lepori, G. M. (2016). Air pollution and stock returns: Evidence from a natural experiment. Journal of Empirical Finance, 35, 25-42. https://doi.org/10.1016/j.jempfin.2015.10.008

Liao, L., Liu, B., \& Wang, H. (2011). Information Discovery in Share Lockups: Evidence from the Split-Share Structure Reform in China. Financial Management, 40(4), 1001-1027. https://doi.org/10.1111/j.1755-053X.2011.01169.x

Liao, L., Zhang, X., \& Zhang, Y. (2017). Mutual fund managers' timing abilities. Pacific-basin Finance Journal, 80-96. https://doi.org/10.1016/j.pacfin.2017.06.003

Morck, R., Yeung, B., \& Yu, W. (2000). The information content of stock markets: why do emerging markets have synchronous stock price movements?. Journal of Financial Economics, 58(1), 215-260. https://doi.org/10.1016/S0304-405X(00)00071-4

Muñoz, F., \& Vicente, R. (2018). Hindsight effect: What are the actual cash flow timing skills of mutual fund investors?. Journal of Empirical Finance, 45, 181-193. https://doi.org/10.1016/j.jempfin.2017.11.004

Oliveira, L., Salen, T., Curto, J. D., \& Ferreira, N. (2018). Market Timing and Selectivity: An Empirical Investigation of European Mutual Fund Performance. International Journal of Economics and Finance, 11(2), 1-16. https://doi.org/10.5539/ijef.v11n2p1

Tang, K., Wang, W., \& Xu, R. (2012). Size and performance of Chinese mutual funds: The role of economy of scale and liquidity. Pacific-Basin Finance Journal, 20(2), 228-246. https://doi.org/10.1016/j.pacfin.2011.09.002

Treynor, J. L., \& Mazuy, K. K. (1966). Can mutual funds outguess the market. Harvard Business Review, 44(4), 
131-136.

Wang, Y., Tsai, J., \& Li, Q. (2017). Policy Impact on the Chinese Stock Market: From the 1994 Bailout Policies to the 2015 Shanghai-Hong Kong Stock Connect. International Journal of Financial Studies, 5(1). https://doi.org/10.3390/ijfs5010004

Wattanatorn, W., \& Tansupswatdikul, P. (2018). An ability to forecast market liquidity - Evidence from South East Asia Mutual fund industry. The Journal of Finance and Data Science, 5(1), $22-32$. https://doi.org/10.1016/j.jfds.2018.10.002.

Yi, L., \& He, L. (2016). False discoveries in style timing of Chinese mutual funds. Pacific-Basin Finance Journal, 38, 194-208. https://doi.org/10.1016/j.pacfin.2016.04.005

Yi, Z. G., \& Mao, N. (2009). Research on the Measurement of Investor Sentiment in Chinese Stock Market: the CICSI's Construction. Journal of Financial Research, 11, 174-184. https://doi.org/CNKI:SUN:JRYJ.0.2009-11-014

Zheng, Y., Osmer, E., \& Zhang, R. (2018). Sentiment hedging: How hedge funds adjust their exposure to market sentiment. Journal of Banking and Finance, 88(3), 147-160. https://doi.org/10.1016/j.jbankfin.2017.11.016

\section{Appendix}

Chinese equity funds

\begin{tabular}{|c|c|}
\hline no & $\begin{array}{l}\text { Fund } \\
\text { code }\end{array}$ \\
\hline 1 & 000082 \\
\hline 2 & 000309 \\
\hline 3 & 000409 \\
\hline 4 & 000411 \\
\hline 5 & 000418 \\
\hline 6 & 000457 \\
\hline 7 & 000471 \\
\hline 8 & 000513 \\
\hline 9 & 000524 \\
\hline 10 & 000549 \\
\hline 11 & 000577 \\
\hline 12 & 000586 \\
\hline 13 & 000592 \\
\hline 14 & 000594 \\
\hline 15 & 000628 \\
\hline 16 & 000688 \\
\hline 17 & 000696 \\
\hline 18 & 000697 \\
\hline 19 & 000711 \\
\hline 20 & 000729 \\
\hline 21 & 000746 \\
\hline 22 & 000751 \\
\hline 23 & 000756 \\
\hline
\end{tabular}

\begin{tabular}{ll}
\hline no & $\begin{array}{l}\text { Fund } \\
\text { code }\end{array}$ \\
\hline 51 & 001036 \\
\hline 52 & 001039 \\
\hline 53 & 001040 \\
\hline 54 & 001042 \\
\hline 55 & 001043 \\
\hline 56 & 001044 \\
\hline 57 & 001047 \\
\hline 58 & 001048 \\
\hline 59 & 001050 \\
\hline 60 & 001054 \\
\hline 61 & 001070 \\
\hline 62 & 001072 \\
\hline 63 & 001097 \\
\hline 64 & 001104 \\
\hline 65 & 001105 \\
\hline 66 & 001126 \\
\hline 67 & 001158 \\
\hline 68 & 001162 \\
\hline 69 & 001163 \\
\hline 70 & 001166 \\
\hline 71 & 001167 \\
\hline 72 & 001171 \\
\hline 73 & 001178 \\
\hline 56 \\
\hline 56
\end{tabular}

\begin{tabular}{|c|c|}
\hline no & $\begin{array}{l}\text { Fund } \\
\text { code }\end{array}$ \\
\hline 101 & 001542 \\
\hline 102 & 001577 \\
\hline 103 & 001583 \\
\hline 104 & 001605 \\
\hline 105 & 001616 \\
\hline 106 & 001626 \\
\hline 107 & 001628 \\
\hline 108 & 001637 \\
\hline 109 & 001638 \\
\hline 110 & 001643 \\
\hline 111 & 001644 \\
\hline 112 & 001645 \\
\hline 113 & 001651 \\
\hline 114 & 001663 \\
\hline 115 & 001672 \\
\hline 116 & 001677 \\
\hline 117 & 001692 \\
\hline 118 & 001703 \\
\hline 119 & 001705 \\
\hline 120 & 001714 \\
\hline 121 & 001717 \\
\hline 122 & 001718 \\
\hline 123 & 001719 \\
\hline
\end{tabular}

\begin{tabular}{ll}
\hline no & $\begin{array}{l}\text { Fund } \\
\text { code }\end{array}$ \\
\hline 151 & 002697 \\
\hline 152 & 002952 \\
\hline 153 & 002980 \\
\hline 154 & 003053 \\
\hline 155 & 003054 \\
\hline 156 & 003145 \\
\hline 157 & 003298 \\
\hline 158 & 003299 \\
\hline 159 & 003416 \\
\hline 160 & 003492 \\
\hline 161 & 003622 \\
\hline 162 & 003623 \\
\hline 163 & 003624 \\
\hline 164 & 003625 \\
\hline 165 & 003634 \\
\hline 166 & 110022 \\
\hline 167 & 160127 \\
\hline 168 & 165310 \\
\hline 169 & $166011 \mathrm{~J}$ \\
\hline 170 & 206012 \\
\hline 171 & 320022 \\
\hline 172 & 376510 \\
\hline 173 & 399011 \\
\hline &
\end{tabular}




\begin{tabular}{|c|c|}
\hline 24 & 000761 \\
\hline 25 & 000778 \\
\hline 26 & 000780 \\
\hline 27 & 000793 \\
\hline 28 & 000803 \\
\hline 29 & 000828 \\
\hline 30 & 000831 \\
\hline 31 & 000854 \\
\hline 32 & 000866 \\
\hline 33 & 000867 \\
\hline 34 & 000884 \\
\hline 35 & 000893 \\
\hline 36 & 000913 \\
\hline 37 & 000916 \\
\hline 38 & 000925 \\
\hline 39 & 000955 \\
\hline 40 & 000960 \\
\hline 41 & 000971 \\
\hline 42 & 000974 \\
\hline 43 & 000978 \\
\hline 44 & 000979 \\
\hline 45 & 000985 \\
\hline 46 & 000991 \\
\hline 47 & 000996 \\
\hline 48 & 001008 \\
\hline 49 & 001009 \\
\hline 50 & 001028 \\
\hline
\end{tabular}

\begin{tabular}{ll}
\hline 74 & 001186 \\
\hline 75 & 001188 \\
\hline 76 & 001193 \\
\hline 77 & 001195 \\
\hline 78 & 001208 \\
\hline 79 & 001223 \\
\hline 80 & 001230 \\
\hline 81 & 001236 \\
\hline 82 & 001245 \\
\hline 83 & 001277 \\
\hline 84 & 001291 \\
\hline 85 & 001313 \\
\hline 86 & 001319 \\
\hline 87 & 001396 \\
\hline 88 & 001404 \\
\hline 89 & 001409 \\
\hline 90 & 001410 \\
\hline 91 & 001416 \\
\hline 92 & 001421 \\
\hline 93 & 001473 \\
\hline 94 & 001476 \\
\hline 95 & 001482 \\
\hline 96 & 001490 \\
\hline 97 & 001496 \\
\hline 98 & 001521 \\
\hline 100 & 001528 \\
\hline 99 & 001541 \\
\hline 89
\end{tabular}

\begin{tabular}{|c|c|}
\hline 124 & 001726 \\
\hline 125 & 001733 \\
\hline 126 & 001736 \\
\hline 127 & 001764 \\
\hline 128 & 001766 \\
\hline 129 & 001781 \\
\hline 130 & 001849 \\
\hline 131 & 001877 \\
\hline 132 & 001878 \\
\hline 133 & 001915 \\
\hline 134 & 001917 \\
\hline 135 & 001938 \\
\hline 136 & 001956 \\
\hline 137 & 001974 \\
\hline 138 & 001975 \\
\hline 139 & 002121 \\
\hline 140 & 002168 \\
\hline 141 & 002210 \\
\hline 142 & 002229 \\
\hline 143 & 002300 \\
\hline 144 & 002332 \\
\hline 145 & 002333 \\
\hline 146 & 002334 \\
\hline 147 & 002335 \\
\hline 148 & 002556 \\
\hline 149 & 002595 \\
\hline 150 & 002621 \\
\hline
\end{tabular}

\begin{tabular}{ll}
\hline 174 & 450009 \\
\hline 175 & 519606 \\
\hline 176 & 519673 \\
\hline 177 & 519714 \\
\hline 178 & 519935 \\
\hline 179 & 519965 \\
\hline 180 & 519975 \\
\hline 181 & 540008 \\
\hline 182 & 540009 \\
\hline 183 & 540010 \\
\hline
\end{tabular}

\section{Copyrights}

Copyright for this article is retained by the author(s), with first publication rights granted to the journal.

This is an open-access article distributed under the terms and conditions of the Creative Commons Attribution license (http://creativecommons.org/licenses/by/4.0/). 